amplification using a modified primer on the $5^{\prime}$ side of codon 542 and subsequent diges tion with Bst NI. ${ }^{8}$ The mutation $(\mathrm{G} \rightarrow \mathrm{T}$ at 1756) was characterised by direct sequencing using the Sequenase USB kit by standard methods. G542 is a nonsense mutation in which a glycine at codon 542 is replaced with a stop codon G542X in the cystic fibrosis transmembrane conductance regulator gene. This boy has a severe lung involvement, meconium ileus, and pancreatic insufficiency, as indicated by the high degree of steatorrhoea. The G542 nonsense mutation was associated with a severe clinical phenotype in the neonatal period.

This case shows that, in contrast to earlier reports, the G542 nonsense mutation alone, which truncates the gene product to $37 \%$ of its length, may lead to severe cystic fibrosis. The explanation for these conflicting results may be resolved by RNA studies. Nevertheless, a severe phenotype in the neonatal period may change with age to a moderate phenotype and vice versa. Environmental, epigenetic and therapeutic factors can influence the clinical course and it is difficult to predict the severity of the disease. This case illustrates again that the presence of any specific CFTR mutation offers little in the way of a prognostic indicator in the individual patient. THIERRY BIENVENU NURIA FONKNECHTEN JEAN CLAUDE KAPLAN GERARD LENOIR

Laboratoire de Biochimie Génétique, Hopital Cochin, 75014 Paris, France, and Service de Pédiatrie, Hôpital Necker Enfants-Malades, 75015 Paris, France.

1 Bonduelle M, Lissens W, Liebaers I, Malfroo A, Dab I. Mild cystic fibrosis in child homozygous for G542 non-sense mutation in CF gene. Lancet 1991;338:189.

2 Beaudet AL, Perciaccante RG, Cutting GR. Homozygous nonsense mutations causing cystic fibrosis with uniparental disomy. $A m$ Hum Genet 1991;48:1213.

3 Cuppens H, Marynen P, De Boeck C, et al. A child, homozygous for a stop codon in exon 11 , shows milder cystic fibrosis symptoms than in her heterozygous nephew. $f$ Med than in her heterozygous

4 Gasparini P, Borgo G, Mastella G, Bonizzato A, Dognini M, Pignatti PF. Nine cystic fibrosis patients homozygous for the CFTR nonsense mutation R1162X have mild or moderate lung disease. $\mathcal{F}$ Med Genet 1992;29:558-62.

5 Bal J, Stuhrmann M, Schloesser M, et al. A cystic fibrosis patient homozygous for the nonsense mutation R553X. F Med Genet 1991;28:715-17.

6 Cheadle J, Al-Jader L, Goodchild M, Meredith AL. Mild pulmonary disease in a cystic fibrosis child homozygous for R553X. $\mathcal{F}$ Med Genet 1992;29:597.

7 Tuddenham EGD, Cooper DN, Gitschier J, et al. Haemophilia A: database of nucleotide al. Haemophilia A: database of nucleotide substitutions, deletions, insertions and rearrangements of the factor
Acids Res 1991;19:4821-33.

$8 \mathrm{Ng}$ ISL, Pace R, Richard MV, et al. Methods for analysis of multiple cystic fibrosis mutations. Hum Genet 1991;87:613-17.

9 Cutting GR, Kalsch LM, Rosenstein BJ, et al. A cluster of cystic fibrosis mutations in the firs nucleotide-binding fold of the cystic fibrosis conductance regulator protein. Natur 1990;346:366-9.

\section{Cutis laxa and the Costello syndrome}

We reported a series of children with cutis laxa in this Journal in 1987. ${ }^{\prime}$ Prompted by a recent article by Kaloustian et $a l^{2}$ on the Costello syndrome, and concerns that our case 5 had some atypical features of cutis laxa, we have taken the opportunity to review this child and found she has now developed nasal papillomata and clearly has the Costello syndrome. This syndrome was originally de- scribed by Costello in the Australian Paediatric fournal in 1977. ${ }^{3}$ The author described two unrelated children with growth and developmental delay together with lax skin and the onset of nasal papillomata in the first decade of life. Two further cases of the syndrome have been reported subsequently. ${ }^{24}$ Since it remains a rare but very characteristic syndrome we would like to update our original case report.

The proband was originally seen when she was $2 \frac{1}{2}$ years of age. At that time the coarse facial features and loose skin had suggested a diagnosis of cutis laxa (fig 1). A subsequent skin biopsy showed that the elastic fibres were normal on histological examination, but there was a relative deficiency of well formed collagen fibres. Her development has continued to be considerably delayed. She walked at 5 years and has received special education. Feeding has remained a problem, although no anatomical or physiological abnormality has been specifically identified. She was treated with growth hormone from 4 years of age and at 10 years her height is $118.5 \mathrm{~cm}$ ( $<3$ rd centile). She has always been relatively macrocephalic (head circumference has been on the 25 th centile) and her anterior fontanelle was late in closing. Her facial features have been relatively coarse with a flat nasal bridge, hypertelorism, downward slanting palpebral fissures, a short neck, and a barrel shaped chest. She has a moderate lumbothoracic scoliosis with limitation of movement at the knees and elbows. There is pes planus with a tendency to walk with the feet in an everted position.

At 6 years of age she developed nasal warts which have tended to recur in spite of aggressive treatment using cryosurgery. She has no warts elsewhere and she has had no adverse reaction to other viral infections. Her routine immunological parameters are normal. Although she is of West Indian origin, her skin is considerably darker than the other members of her family especially over the dorsum of her hands. Hyperpigmentation has also been reported in previous cases of Caucasian origin. One of the striking features which distinguishes this syndrome from other causes of cutis laxa is the deep palmar creases and thickened dermal ridges which have an unusual 'velvety' feel (fig 2). isolated cases. In this family the parents have
All cases of Costello syndrome have been had a further unaffected son since the ori-

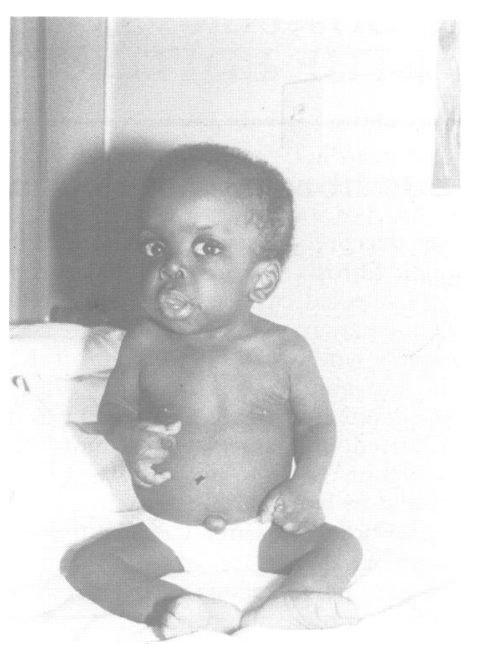

Figure 1 Patient at 2 years of age when reported as an example of cutis laxa. Note the lax skin is most marked over the hands and feet. There is short stature and relative macrocephaly.

ginal report. The inheritance pattern therefore remains unclear.

MICHAEL A PATTON Department of Clinical Genetics, St George's Hospital Medical School, Cranmer Terrace, London SW17 ORE, UK.

MICHAEL BARAITSER Institute of Child Health, 30 Guilford Street,

London WCIN 1EH, UK.

1 Patton MA, Tolmie J, Ruthnum P, Bamforth S, Baraitser $M$, Pembrey $M$. Congenital cutis laxa with retardation of growth and development. F Med Genet 1987;24:556-61.

2 Kaloustian VMD, Moroz B, McIntosh N, Watters K, Blaichman S. Costello syndrome. Am f Med Genet 1991;41:69-73.

3 Costello JM. A new syndrome: mental subnormality and nasal papillomata. Aust Paediatr $\mathcal{F}$ mality and nasal

4 Santos HG. Costello syndrome: another case. European Society of Human Genetics, Denmark, 1992, Abst 251.

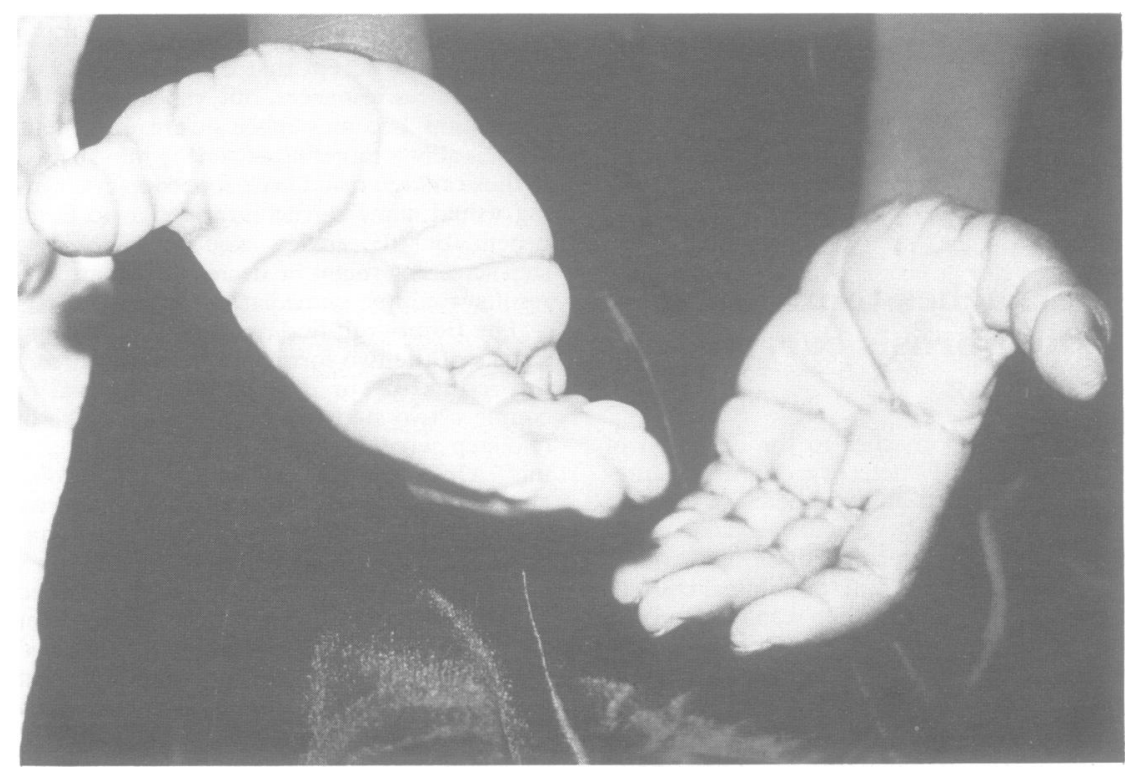

Figure 2 The dermal creases are very marked and the palms of the hands are 'velvety' to feel. This feature was present from an early stage before the nasal papillomata developed and is a useful sign to distinguish the Costello syndrome from other causes of cutis laxa. 